\title{
BMJ Open Association of workplace social capital with psychological distress: results from a longitudinal multilevel analysis of the J-HOPE Study
}

\author{
Hisashi Eguchi, ${ }^{1,2}$ Akizumi Tsutsumi, ${ }^{2}$ Akiomi Inoue, ${ }^{2}$ Hiroyuki Hikichi, ${ }^{3}$ \\ Ichiro Kawachi $^{3}$
}

To cite: Eguchi H, Tsutsumi A, Inoue A, et al. Association of workplace social capital with psychological distress: results from a longitudinal multilevel analysis of the J-HOPE Study. BMJ Open 2018;8:e022569. doi:10.1136/ bmjopen-2018-022569

- Prepublication history and additional material for this paper are available online. To view these files, please visit the journal online (http://dx.doi org/10.1136/bmjopen-2018022569).

Received 23 February 2018 Revised 29 0ctober 2018 Accepted 14 November 2018

D) Check for updates

(C) Author(s) (or their employer(s)) 2018. Re-use permitted under CC BY-NC. No commercial re-use. See rights and permissions. Published by BMJ.

${ }^{1}$ Takemi Program in International Health, Harvard T. H. Chan School of Public Health, Boston, Massachusetts, USA

${ }^{2}$ Department of Public Health, Kitasato University School of Medicine, Sagamihara, Japan

${ }^{3}$ Department of Social and Behavioral Sciences, Harvard T. H. Chan School of Public Health, Boston, Massachusetts, USA

Correspondence to

Dr Hisashi Eguchi;

eguchi@med.kitasato-u.ac.jp

\section{ABSTRACT}

Objectives Workplace social capital (WSC) is increasingly recognised as a social contextual determinant of workers' mental health, but longitudinal data are sparse. We aimed to evaluate the impact of changes in unit-level WSC on psychological distress among Japanese employees using a prospective multilevel repeated-measures design.

Participants and study design We conducted a 2-year prospective cohort study with 1,944 men and 786 women aged $18-65$ years. Participants worked at two manufacturing worksites in Japan and were free from mental illness from the first to third study waves. We used a three-level multilevel regression design to evaluate the prospective association of unit-level WSC with individuallevel psychological distress. WSC was measured using a validated six-item instrument and individual-level psychological distress with the Kessler Psychological Distress Scale (K6).

Results The null model indicated a significant degree of between-work unit variation in psychological distress (intraclass correlation $=0.1 \%, p<0.001$ ). In the full model, each SD increase in unit-level WSC was associated with 0.69 point improvement in $\mathrm{K} 6$ scores $(95 \% \mathrm{Cl}-1.12$ to $-0.26)$.

Conclusions This prospective study builds on existing knowledge by showing an association between unitlevel WSC and modest improvements in mental health among employees in Japan. We recommend that WSC is considered alongside other contextual influences when assessing employees' mental health risks.

\section{INTRODUCTION}

Social capital is defined as resources accessed by individuals as a result of their membership of a network or group. ${ }^{1}$ Workplace social capital (WSC) has attracted increased attention as a potentially important organisational/contextual influence on workers' mental health. ${ }^{1}$ A previous study from Finland demonstrated an association between WSC and various mental health indicators. ${ }^{2}$ Employees' mental health has also emerged as a critical concern in recent years. ${ }^{3}$
Strengths and limitations of this study

- A strength of our study is that we evaluated the impact of a change in work unit social capital on changes in individual workers' psychological distress (first differences design).

- The use of a self-administered questionnaire to assess both exposures and outcome might have produced common method bias.

- The generalisability of the results is uncertain, because workplace social capital depends on the prevailing norm and culture of an organisation and the sample for this study was drawn from a single company.

The pathways linking social capital to health outcomes vary by level of analysis. ${ }^{1}$ In this paper, we have focused on social capital as a group-level construct. Group-level WSC can bring benefits to individuals, probably through increased emotional support and respect from co-workers, which can reduce psychophysiological stress responses to physically strenuous jobs. ${ }^{4}$

Four cross-sectional and six longitudinal studies have investigated the association between WSC and mental illness. ${ }^{5-14}$ A 4-year prospective study demonstrated the impact of changes in individual-level WSC on changes in mental health. ${ }^{11}$ Another 5-year prospective multilevel study found that organisational-level WSC was not associated with mental health problems. ${ }^{9}$ However, that study assessed unit-level WSC at baseline only and did not update exposure during follow-up. ${ }^{9}$ Therefore, the impact of a change in unit-level WSC on a worker's psychological distress remains unknown. For example, employees' perceptions of WSC as well as the association between social capital and psychological distress may fluctuate with the business cycle. $^{1516}$ 
Baseline questionnaire survey

from April to June 2011

2nd wave survey
from April to June 2012

3rd wave survey

from April to June 2013
Enrollment in the baseline survey $(n=3,630)$

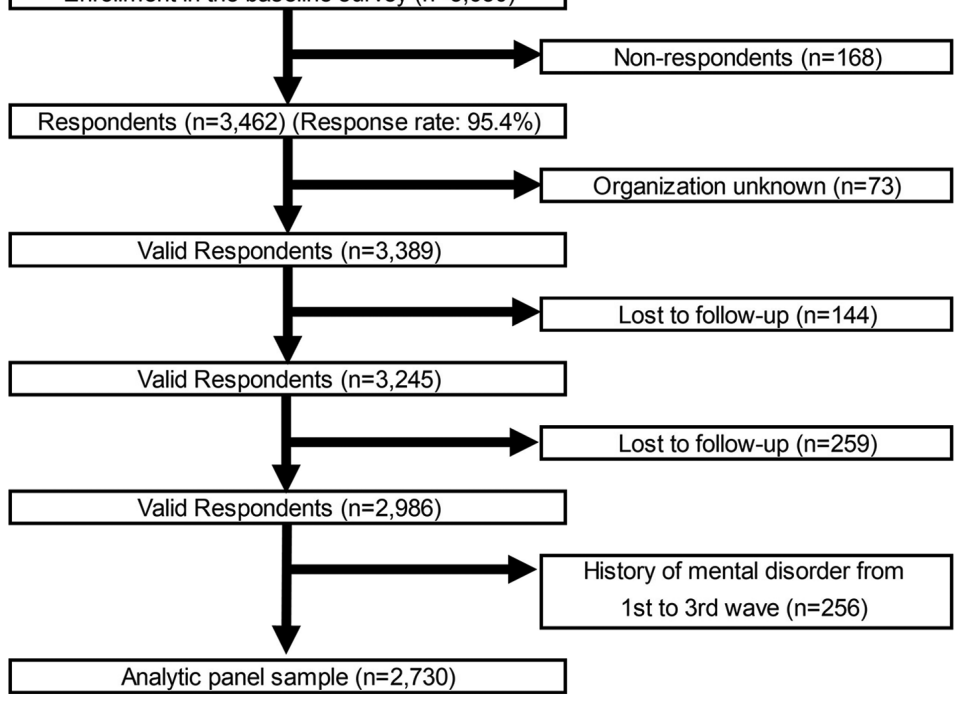

Figure 1 Flow of participants for the study sample $(n=2730)$.

In this study, we constructed a multilevel analysis using three levels (repeated measurements of psychological distress nested within individual employees, then work units) to evaluate the impact of a change in unit-level WSC on individual workers' psychological distress. We used panel data from three waves of the Japanese Study of Health, Occupation, and Psychosocial Factors Related Equity (J-HOPE), an occupational cohort study on social class and health in Japan that involved 21 work units.

\section{METHODS}

\section{Participants and study design}

Written consent was obtained from participants.

This study was conducted as part of J-HOPE, a largescale workplace-based prospective study involving around 10,000 workers in Japan. ${ }^{1117}$ We used data from the baseline, second and third wave surveys for 1 of the 12 participating J-HOPE sites, based on the availability of exposure data (ie, unit-level information). A detailed flow chart of the study sample is shown in figure 1. We conducted a 2-year prospective cohort study with workers aged 18-65 years $(n=3,630)$ at two manufacturing sites operated by an electrical components company in the Osaka region of Japan. All employees at the two sites were invited to participate in the J-HOPE baseline survey, conducted from April to June 2011. The second and third waves were conducted from April to June 2012 and from April to June 2013. Data were collected using a self-administered questionnaire that included items about psychosocial factors, and demographic and lifestyle characteristics. The original sample included 3,462 respondents in the first wave; 3,344 in the second wave (follow-up rate 95.8\%); and 3,179 in the third wave (follow-up rate $88.1 \%$ ). We excluded participants who did not participate in all three survey waves and anyone who reported a history of mental disorder in any of the three survey waves. This resulted in a sample of 2730 employees for the analysis. The analysis was conducted with the J-HOPE data set as on 22 December 2016. 'Work unit' at the two manufacturing sites was defined by division, of which there were 21 .

We compared the baseline characteristics of the study population $(n=3,462)$ with those lost to follow-up $(n=694)$. At baseline, there were no significant differences between the two groups by sex, weekly working hours, annual family income, chronic diseases, smoking status, body mass index (BMI), job strain or psychological distress. However, workers lost to follow-up were older, had a higher occupational status, worked in units with a higher proportion of employees with higher education, drank alcohol more often and reported higher levels of physical exercise.

\section{Dependent variable: psychological distress}

Psychological distress was assessed using the Kessler Psychological Distress Scale (K6). The K6 was originally developed as a screening instrument for non-specific psychological distress and serious mental illness. Its internal reliability and validity have been documented. ${ }^{18}$ The K6 consists of a six-item battery asking how frequently respondents had experienced symptoms of psychological distress in the past 30 days. Responses range from ' 0 ' (none of the time) to ' 4 ' (all of the time), with total scores ranging from 0 to 24 . The $\mathrm{K} 6$ has been translated into Japanese, and the Japanese version has been validated. ${ }^{19}$ In this sample, Cronbach's $\alpha$ coefficients for K6 were 0.88 in the first wave, 0.89 in the second wave and 0.89 in the third wave.

\section{Independent variable: WSC}

WSC was the main independent variable of interest. To assess this, we used a validated six-item instrument to measure bonding WSC, with each item scored on a fourpoint Likert Scale: 1: strongly disagree, 2: disagree, 3: agree, 4: strongly agree. The responses were summed, resulting in individual WSC scores from 6 to 24 with 
higher scores indicating higher WSC. The internal consistency of the scale was acceptably high in each survey, with Cronbach's $\alpha$ coefficients for the six-item WSC scale of 0.89 in the first wave, 0.90 in the second wave and 0.90 in the third wave. The items in the measure are: 'People keep each other informed about work-related issues in the work unit', 'We have a 'we are together' attitude', 'People feel understood and accepted by each other', 'In our workplace, there is an atmosphere of helping each other', 'In our workplace, we trust each other', and 'Our workplace is a place of laughter and smiles'. The WSC scale has acceptable reliability and validity, described in detail elsewhere.$^{20}$ In brief, the scale includes items relevant to bonding WSC to measure the network, trust and reciprocity aspects of the concepts.

Unit-level WSC (level 3) was calculated as the mean of individual (level 1) responses from co-workers in the same work unit. To avoid multicollinearity, we orthogonalised individual-level and unit-level WSC by mean-centring; that is, by subtracting unit-level values (average of individual-level responses) from individual-level values.

\section{Measurement of covariates}

The demographic and lifestyle characteristics that were measured based on previous studies about the risk factor for psychological distress were sex, age, education, ${ }^{21}$ BMI, ${ }^{22}$ job strain, ${ }^{23}$ occupation, ${ }^{24}$ employment contract, ${ }^{25}$ weekly working hours, ${ }^{26}$ annual family income, ${ }^{27}$ chronic medical illness, ${ }^{28}$ smoking status, ${ }^{29}$ frequency of alcohol drinking ${ }^{30}$ and physical exercise. ${ }^{31}$ Employment contract and work-unit information were obtained from the company. BMI was calculated from health check-up results by dividing weight $(\mathrm{kg})$ by the square of height $\left(\mathrm{m}^{2}\right)$. We used the Job Content Questionnaire to measure psychological demands and decision latitude. ${ }^{32}$ The psychological demand scale has five items, including 'Work fast' and 'Work hard' (response range: 12-48), and the decision latitude scale consists of nine items, including 'Learn new things' and 'Repetitive work' (response range: 24-96). Cronbach's $\alpha$ coefficients for psychological demands and decision latitude were, respectively, 0.67 and 0.82 in the first wave, 0.69 and 0.81 in the second wave, and 0.70 and 0.81 in the third wave. Based on a previous study, ${ }^{33}$ we defined job strain as the ratio of psychological demands score $\times 2$ to the decision latitude score, expressed as a continuous variable. Age, BMI and job strain were expressed as continuous variables. Educational attainment was categorised into five groups: 11 years or less, 12-13 years, 14-15 years, 16-17 years and 18 years or more spent in education. We classified occupation based on the International Standard Classification of Occupations, which is based on skill level and skill specialisation. ${ }^{34}$ Participants chose one of nine options: (1) managers; (2) professionals; (3) technicians and associate professionals; (4) clerical support workers; (5) service and sales workers; (6) craft and related trade workers; (7) plant and machine operators and assemblers; (8) armed forces occupations; and (9) others.
Responses were divided into four categories: managers, non-manual workers (professionals, technicians and associate professionals, clerical support workers, and service and sales workers), manual workers (craft and related trade workers, plant and machine operators and assemblers, and armed forces occupations) and others. Employment contract was categorised as regular or part-time. Weekly working hours were categorised as: $\leq 30$ hours, 31-40 hours, 41-50 hours, 51-60 hours and $\geq 61$ hours per week. Study participants were asked to indicate their annual family income from six income bands: (1) less than 3 million yen; (2) 3-5 million yen; (3) 5-8 million yen; (4) 8-10 million yen; (5) 10-15 million yen; and (6) more than 15 million yen. Past history or current experience of chronic physical conditions was assessed by multiple choice. Conditions included hypertension, diabetes mellitus, hyperlipidaemia, stroke, myocardial infarction and cancer. Smoking status was categorised as never smoked, former smoker or current smoker. Frequency of alcohol drinking was classified as does not drink, drinks but not everyday or drinks every day. Physical exercise was classified as no exercise, light exercise more than once a week, heavy exercise once or twice a week, or heavy exercise more than three times a week. We defined 'light exercise' as exercise that did not produce shortness of breath or elevated heart rate, and 'heavy exercise' as exercise causing shortness of breath and elevated heart rate.

\section{Statistical analysis}

Multilevel modelling was performed by considering the association between different levels, with time nested within individuals, then within workplace. By adding a random part in the analysis, the technique accounts for dependence between different levels, allowing the intercept coefficients to vary among different work units. Variance partition coefficient (VPC) was used to estimate the proportion of total variance in $\mathrm{K} 6$ scores attributable to the work unit.

We estimated a null model that included only a random intercept and allowed us to estimate the intraclass correlation coefficient (ICC(1)) ${ }^{35} 36$ ICC (1) was $4.0 \%(\mathrm{p}<0.001)$ in the first wave, $3.5 \%(\mathrm{p}<0.001)$ in the second wave and $4.0 \%(\mathrm{p}<0.001)$ in the third wave, indicating significant variance in individual WSCs between work units.

We also used a within-group agreement index $\left(r_{w g}\right)$ to measure the validity of individual responses. The $r_{w g}$ is calculated by comparing an observed group variance with an expected random variance. ${ }^{37}{ }^{38} \mathrm{~A}$ higher $r_{w g}$ indicates that social capital may be treated as a contextual phenomenon and supports the aggregation of unit members' perception of the phenomenon to form the derived variable. The $r_{w g}$ of WSC in work units was $0.67-0.82$ in the first wave, $0.66-0.89$ in the second wave and 0.79-0.92 in the third wave. An $r_{w g}$ over 0.7 supports homogeneity in perceptions of the phenomenon. ${ }^{39}$

The longitudinal analysis was performed with time (at level 1), individuals (at level 2) and work unit (at level 3). 
Three models were run, with the cumulative measure of $\mathrm{K} 6$ regressed on work units in the empty model (model 0 ), with individual-level WSC and all individual-level variables included in model 1 , with a full model including all individual-level and work unit-level variables and work unit-level WSC and workplace size included in model 1 as random-effects parts (model 2). We standardised all explanatory variables before inclusion in the multilevel analysis.

To address potential bias resulting from missing data, we used multiple imputation by the Markov Chain Monte Carlo method assuming that data were missing at random for explanatory variables and covariates. We created 50 imputed data sets and combined each analysis result using the STATA command 'mi estimate.' All analyses were performed with STATA V.14.0 (STATA). We defined statistical significance as a two-sided $\mathrm{p}$ value $<0.05$.

\section{Patient and public involvement}

No participants were involved in developing the research question, outcome measures and overall design of the study. Due to participant anonymity, we are unable to disseminate the results of the research directly to study participants.

\section{RESULTS}

Table 1 summarises the participants' characteristics. The majority of the participants were male $(71.2 \%)$ and the mean age was 38.8 years $(\mathrm{SD}=10.9)$ (table 1$)$. The largest occupational group was manual workers. About $80 \%$ of our sample was employed full time and about $30 \%$ worked $41-50$ hours per week in the time between the first and third surveys.

Table 2 shows the workplace characteristics. The mean unit-level social capital was $16.3(\mathrm{SD}=2.8)$ to 17.1 $(\mathrm{SD}=0.5$ and 0.8$)$ in the first survey, $16.1(\mathrm{SD}=2.1)$ to 17.3 $(\mathrm{SD}=0.2)$ in the second survey and $16.4(\mathrm{SD}=0.0)$ to 17.4 $(\mathrm{SD}=1.0)$ in the third survey.

Table 3 shows the three-level hierarchical regression results. The null model indicated a significant amount of variation in psychological distress between workplaces (ICC $=0.1 \%, \mathrm{p}<0.001)$. Random effects in the initial empty model showed that $50.5 \%$ of the average variation in psychological distress was attributed to clustering by individuals over time, while $0.1 \%$ was attributed to clustering by work units over time. In model 1 , individual-level WSC showed a significant association with psychological distress (coefficient $=-0.83 ; 95 \%$ CI -0.92 to -0.73 ). In model 2, the VPC at the work unit level was $6.9 \%$. Unitlevel WSC was significantly related to change in psychological distress (coefficient $=-0.69 ; 95 \% \mathrm{CI}-1.12$ to $-0.26)$. This equated to an average improvement in $\mathrm{K} 6$ scores of roughly 0.69 points over 3 years for every SD change in unit-level WSC. Similarly, individual-level WSC was significantly related to psychological distress (coefficient $=-0.84 ; 95 \% \mathrm{CI}-0.94$ to -0.74 ). In summary, the
Table 1 Characteristics of eligible participants in each survey wave $(2011-2013)(n=2,730)$

\begin{tabular}{|c|c|c|c|}
\hline Characteristics & $\begin{array}{l}\text { First } \\
\text { survey }\end{array}$ & $\begin{array}{l}\text { Second } \\
\text { survey }\end{array}$ & $\begin{array}{l}\text { Third } \\
\text { survey }\end{array}$ \\
\hline \multicolumn{4}{|l|}{ Sex } \\
\hline Male & $1,944(71.2)$ & & \\
\hline Female & $786(28.8)$ & & \\
\hline Age, years (SD) & $38.8(10.9)$ & & \\
\hline \multicolumn{4}{|l|}{ Education (years), n (\%) } \\
\hline 11 or less & $43(1.6)$ & $43(1.6)$ & $39(1.4)$ \\
\hline $12-13$ & $1,608(58.9)$ & $1,621(59.4)$ & $1,579(57.8)$ \\
\hline $14-15$ & $502(18.4)$ & $497(18.2)$ & $473(17.3)$ \\
\hline $16-17$ & $324(11.9)$ & $326(11.9)$ & $314(11.5)$ \\
\hline 18 or more & $193(7.1)$ & $198(7.3)$ & $180(6.6)$ \\
\hline Missing & $60(2.2)$ & $45(1.6)$ & $145(5.3)$ \\
\hline WSC, mean (SD) & $16.9(3.3)$ & $17.1(3.0)$ & $17.0(3.1)$ \\
\hline $\begin{array}{l}\text { Psychological distress, } \\
\text { mean (SD) }\end{array}$ & $5.4(4.4)$ & $4.2(4.2)$ & $4.2(4.2)$ \\
\hline BMI, mean (SD) & $22.8(3.6)$ & $22.9(3.6)$ & $23.0(3.7)$ \\
\hline Job strain, mean (SD) & $0.5(0.1)$ & $0.5(0.1)$ & $0.5(0.1)$ \\
\hline \multicolumn{4}{|l|}{ Occupation, n (\%) } \\
\hline Manager & $219(8.0)$ & $244(8.9)$ & $249(9.1)$ \\
\hline Non-manual worker & $694(25.4)$ & $701(25.7)$ & $656(24.0)$ \\
\hline Manual worker & $1,275(46.7)$ & $1,211(44.4)$ & 1,197 (43.8) \\
\hline Others & $446(16.3)$ & $494(18.1)$ & $481(17.6)$ \\
\hline Missing & $96(3.5)$ & $80(2.9)$ & $147(5.4)$ \\
\hline \multicolumn{4}{|c|}{ Employment contract, $\mathrm{n}(\%)$} \\
\hline Regular employee & $2,228(81.6)$ & $2,225(81.5)$ & $2,130(78.0)$ \\
\hline Part-time employee & $502(18.4)$ & $492(18.0)$ & $492(18.0)$ \\
\hline Missing & $0(0.0)$ & $13(0.5)$ & $108(4.0)$ \\
\hline \multicolumn{4}{|c|}{ Weekly working hours, $\mathrm{n}(\%)$} \\
\hline 30 or less & $616(22.6)$ & $554(20.3)$ & $514(18.8)$ \\
\hline $31-40$ & $589(21.6)$ & $806(29.5)$ & $695(25.5)$ \\
\hline $41-50$ & 905 (33.2) & $838(30.7)$ & $872(31.9)$ \\
\hline $51-60$ & $427(15.6)$ & $343(12.6)$ & $401(14.7)$ \\
\hline 61 or more & $136(5.0)$ & $128(4.7)$ & $119(4.4)$ \\
\hline Missing & $57(2.1)$ & $61(2.2)$ & $129(4.7)$ \\
\hline \multicolumn{4}{|c|}{ Annual family income (million yen), $\mathrm{n}(\%)$} \\
\hline$<3$ & $357(13.1)$ & $313(11.5)$ & $318(11.6)$ \\
\hline $3-5$ & $675(24.7)$ & $775(28.4)$ & $695(25.5)$ \\
\hline $5-8$ & 1,066 (39.0) & 1,021 (37.4) & 998 (36.6) \\
\hline $8-10$ & $348(12.7)$ & 316 (11.6) & 314 (11.5) \\
\hline $10-15$ & $193(7.1)$ & $194(7.1)$ & 172 (6.3) \\
\hline $15+$ & $21(0.8)$ & $21(0.8)$ & $21(0.8)$ \\
\hline Missing & $70(2.6)$ & 90 (3.3) & $212(7.8)$ \\
\hline \multicolumn{4}{|l|}{ Chronic disease } \\
\hline No & 2,109 (77.3) & $2,164(79.3)$ & 2,081 (76.2) \\
\hline Yes & $371(13.6)$ & 435 (15.9) & 448 (16.4) \\
\hline Missing & $250(9.2)$ & $131(4.8)$ & $201(7.4)$ \\
\hline
\end{tabular}

Continued 


\begin{tabular}{|c|c|c|c|}
\hline Characteristics & $\begin{array}{l}\text { First } \\
\text { survey }\end{array}$ & $\begin{array}{l}\text { Second } \\
\text { survey }\end{array}$ & $\begin{array}{l}\text { Third } \\
\text { survey }\end{array}$ \\
\hline \multicolumn{4}{|l|}{ Smoking status, n (\%) } \\
\hline Never & $1,574(57.7)$ & $1,552(56.8)$ & $1,495(54.8)$ \\
\hline Former & $231(8.5)$ & $224(8.2)$ & $243(8.9)$ \\
\hline Current & $894(32.7)$ & 909 (33.3) & $874(32.0)$ \\
\hline Missing & $31(1.1)$ & $45(1.6)$ & $118(4.3)$ \\
\hline \multicolumn{4}{|c|}{ Frequency of alcohol drinking, n (\%) } \\
\hline None & $1,316(48.2)$ & $1,290(47.3)$ & $1,291(47.3)$ \\
\hline Sometimes & $825(30.2)$ & $810(29.7)$ & $783(28.7)$ \\
\hline Everyday & $560(20.5)$ & $588(21.5)$ & $540(19.8)$ \\
\hline Missing & $29(1.1)$ & $42(1.5)$ & $116(4.2)$ \\
\hline \multicolumn{4}{|l|}{ Physical exercise, n (\%) } \\
\hline None & $1,872(68.6)$ & $1,771(64.9)$ & $1,771(64.9)$ \\
\hline $\begin{array}{l}\text { Light exercise more } \\
\text { than once a week }\end{array}$ & $487(17.8)$ & $554(20.3)$ & $511(18.7)$ \\
\hline $\begin{array}{l}\text { Heavy exercise once } \\
\text { or twice a week }\end{array}$ & $240(8.8)$ & $251(9.2)$ & $224(8.2)$ \\
\hline $\begin{array}{l}\text { Heavy exercise more } \\
\text { than three times a } \\
\text { week }\end{array}$ & $46(1.7)$ & $80(2.9)$ & $73(2.7)$ \\
\hline Missing & $85(3.1)$ & $74(2.7)$ & $151(5.5)$ \\
\hline
\end{tabular}

BMI, body mass index; WSC, workplace social capital.

longitudinal analysis showed that unit-level WSC was associated with mental health over a 3-year period.

\section{DISCUSSION}

Our prospective study sought to contribute to the discussion on WSC and health by analysing the contextual influence of unit-level WSC on individual psychological distress across a 3-year period. Our findings suggested that unitlevel WSC had a slightly favourable impact on individuals' psychological distress (ICC $=0.1 \%$ in the null model). The impact of unit-level WSC on an individual's psychological distress $($ coefficient $=-0.69 ; 95 \% \mathrm{CI}-1.12$ to -0.26 ) was about three quaters that of individual-level WSC (coefficient $=-0.84 ; 95 \% \mathrm{CI}-0.94$ to -0.74 ), and the same as that of job strain (coefficient $=0.62 ; 95 \%$ CI 0.53 to 0.72 ). However, unit-level WSC was comparable with the impact of occupation (coefficient $=-0.19 ; 95 \%$ CI -0.31 to -0.07 ), chronic disease (coefficient $=0.14 ; 95 \%$ CI 0.03 to 0.25 ) and annual familial income $($ coefficient $=-0.24 ; 95 \% \mathrm{CI}-0.35$ to -0.13 ). These findings emphasise the contextual importance of unit-level WSC for workers' psychological distress.

To our knowledge, this is the first study of its kind to examine the influence of unit-level and individual-level WSC on psychological distress, using a multilevel prospective repeated-measures design. The only previously published study on this topic found that a higher perception of WSC among workers was associated with lower ORs for antidepressant treatment and physician-diagnosed depression. ${ }^{9}$ However, the study found that unit-level WSC was not associated with depression outcomes after controlling for individual perceptions. ${ }^{9}$ An explanation for these divergent results might be cultural differences in the workplace. Bonding social capital is particularly important in Japanese workplaces, because Japanese culture has a group orientation. Altruism, teamwork and group cohesiveness are emphasised in Japanese society, and individual identity is often subsumed within social group identity. ${ }^{40} 41$

In our crude analyses, the ICC for social capital was only $0.1 \%$, indicating that a substantial proportion of the variance of individual social capital is between work units. This is quite low compared with the previous studies. ${ }^{49} 392$ The reason for this discrepancy may be the number of work units and the repeated-measures design. Smaller number of individual employees per work units may show larger ICCs (number of participants/number of work units) such as $32,053 / 2,182,{ }^{4} 9,524 / 1,522,{ }^{39}$ and $2,043 / 260 .{ }^{42}$ No previous studies have used the repeated measures of psychological distress. ${ }^{4} 3942$ The repeated measures may decrease ICC, which indicates the amount of variation in psychological distress between workplaces. The VPC at the work unit level was $6.9 \%$ which was in line with previous studies. ${ }^{493942}$

Table 2 Workplace characteristics and workplace social capital $(n=21)$

\section{Workplace size}

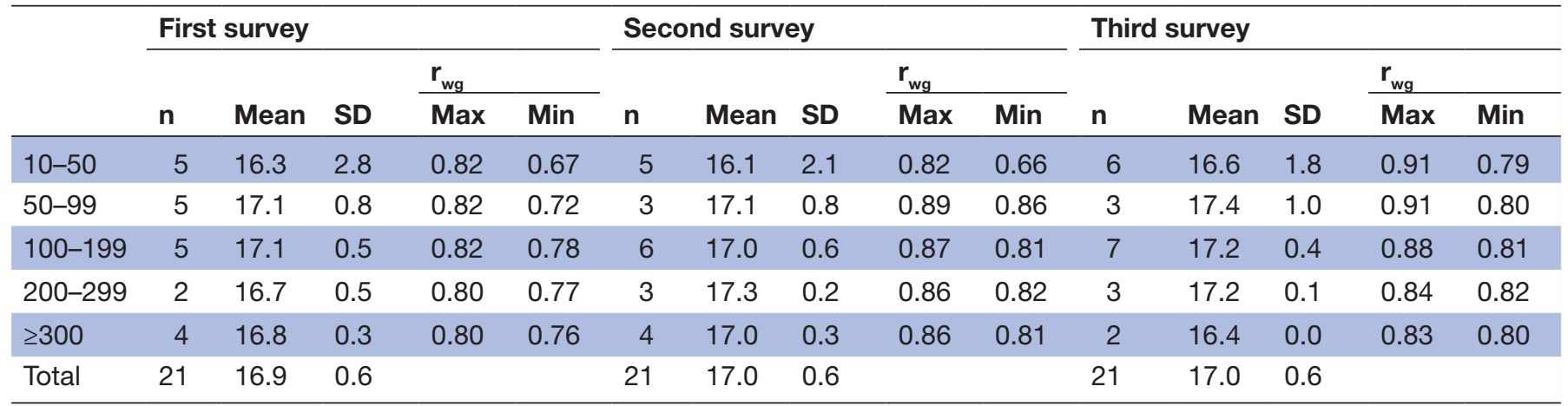

$r_{\text {wg }}$, within-group agreement index. 
Table 3 Associations between work unit-level/individual-level social capital and K6

\begin{tabular}{|c|c|c|c|}
\hline & Model 0 & Model 1 & Model 2 \\
\hline Estimates & Coefficient $(95 \% \mathrm{Cl})$ & Coefficient $(95 \% \mathrm{Cl})$ & Coefficient $(95 \% \mathrm{Cl})$ \\
\hline Intercept & 4.57 (4.41 to 4.73$)$ & 4.55 (4.36 to 4.74$)$ & 4.65 (4.17 to 4.99$)$ \\
\hline \multicolumn{4}{|l|}{ Work unit level } \\
\hline Workplace social capital & & & $-0.69(-1.12$ to -0.26$)$ \\
\hline Workplace size & & & $0.09(-0.22$ to 0.41$)$ \\
\hline \multicolumn{4}{|l|}{ Individual level fixed effects } \\
\hline Workplace social capital & & $-0.83(-0.92$ to -0.73$)$ & $-0.84(-0.94$ to -0.74$)$ \\
\hline Sex & & $0.13(-0.06$ to 0.32$)$ & $0.14(-0.06$ to 0.33$)$ \\
\hline Age & & $-0.63(-0.78$ to -0.48$)$ & $-0.58(-0.73$ to -0.43$)$ \\
\hline Educational attainment & & $-0.18(-0.31$ to -0.04$)$ & $-0.17(-0.31$ to -0.03$)$ \\
\hline Occupation & & $-0.19(-0.31$ to -0.07$)$ & $-0.19(-0.31$ to -0.07$)$ \\
\hline Employment contract & & $-0.30(-0.50$ to -0.11$)$ & $-0.34(-0.54$ to -0.14$)$ \\
\hline Weekly working hours & & $0.03(-0.08$ to 0.15$)$ & $0.04(-0.08$ to 0.15$)$ \\
\hline Annual familial income & & $-0.23(-0.34$ to -0.12$)$ & $-0.24(-0.35$ to -0.13$)$ \\
\hline Chronic disease & & 0.14 (0.03 to 0.25$)$ & 0.14 (0.03 to 0.25$)$ \\
\hline Smoking status & & $-0.04(-0.17$ to 0.08$)$ & $-0.05(-0.18$ to 0.07$)$ \\
\hline Frequency of alcohol drinking & & $-0.01(-0.13$ to 0.10$)$ & $-0.02(-0.14$ to 0.09$)$ \\
\hline Physical exercise & & $-0.09(-0.18$ to 0.01$)$ & $-0.07(-0.17$ to 0.02$)$ \\
\hline $\mathrm{BMI}$ & & $-0.04(-0.16$ to 0.09$)$ & $-0.03(-0.15$ to 0.10$)$ \\
\hline Job strain & & 0.64 (0.54 to 0.74$)$ & 0.62 (0.53 to 0.72$)$ \\
\hline \multicolumn{4}{|l|}{ Random effects } \\
\hline Work unit level variance & 0.13 & 0.27 & 0.88 \\
\hline Workplace social capital & & & 0.43 \\
\hline Workplace size & & & 0.49 \\
\hline Individual level variance & 3.08 & 2.75 & 2.76 \\
\hline Time level variance & 3.05 & 2.96 & 2.92 \\
\hline VPC workplace & $0.1 \%$ & $0.4 \%$ & $6.9 \%$ \\
\hline VPC individual & $50.5 \%$ & $46.2 \%$ & $45.1 \%$ \\
\hline VPC time & $49.4 \%$ & $53.4 \%$ & $50.3 \%$ \\
\hline
\end{tabular}

BMI, body mass index; K6, Kessler Psychological Distress Scale; VPC, variance partition coefficient.

The concepts of workplace social support and WSC are related. ${ }^{1}$ For example, a workplace with high social cohesion and solidarity (ie, high social capital) is likely to be one where employees receive social support from their co-workers and supervisors. ${ }^{1}$ There are, however, some significant differences between the concepts. Workplace social support is a resource that individual workers can access. ${ }^{1}$ Even in the same workplace, there may be inequalities in receipt of social support, that is, some workers will receive more than others. WSC, however, is a property of the workplace, not the individual. ${ }^{43}{ }^{44}$ In our multilevel analysis, we aggregated workers' perceptions about cohesion and solidarity up to the work unit level. WSC is therefore a group-level concept and distinct from individual reports of social support.

Unit-level WSC can be hypothesised to influence employees' psychological distress in several ways. Kawachi and Berkman ${ }^{1}$ set out several mechanisms by which group-level social capital exerted a contextual effect on individual health, including: (1) Reciprocity and mutual support. (2) Informal social control and the maintenance of group norms. (3) Collective efficacy. This might be because in a more cohesive workplace, it is easier to achieve coordination and cooperation among employees, ${ }^{45}$ which might reduce employees' psychological distress. Another potential explanation is that workplaces in which workers have similar values about workplace norms and intervene when these norms are violated are believed to collectively discourage antisocial behaviour. Workplace collective efficacy may be associated with fewer problem behaviours that lead to workers' mental health problems. However, WSC may also have a 'dark side' in Japanese workplaces in terms of employee health. ${ }^{46}$ High cohesion of a unit as indicated by high WSC might be associated with more 
bullying of those who do not 'fit' in the organisational culture. It has also been reported that depression is contagious across social networks. ${ }^{47}$

Unit-level variation of WSC was significant. In the workplace, managers may play an important role in boosting unit-level WSC. Previous community-based intervention studies suggested that work unit social activities may strengthen WSC. ${ }^{48}{ }^{49}$ Examples of interventions to promote WSC include scheduling athletic competitions (undokai) within the company, and social activities such as weekend corporate retreats (shain-ryoko) and cherry blossom viewing picnic parties (hanami).

This study had some limitations. First, the use of a self-administered questionnaire to assess both exposures and outcomes might have produced common method bias. This possibility was reduced in the multilevel analysis because each worker was assigned the average value of all workers in the same unit. Second, the generalisability of our results is unclear, because WSC depends on the prevailing norm and culture of an organisation and the sample for this study was drawn from a single company. Third, the definition of 'workplace' is ambiguous, and the questionnaire did not specify the organisational unit in detail. It is therefore possible that different participants interpreted the question differently. Fourth, although we controlled for a range of individual-level and unit-level covariates, we cannot rule out bias from unmeasured confounding. Fifth, there may be other social and economic factors that should have been considered. Workplace bullying plays a significant role in mediating the association between psychosocial factors and psychological distress. ${ }^{50}$ Economic crises may also have a potential additional negative impact on workers' mental health. ${ }^{52-54}$ In Japan, suicide as a result of psychological distress was a significant public health concern for working-aged men after the 'bubble economy' collapsed. ${ }^{24}$ These social and economic conditions in Japan may therefore affect the association between organisational psychosocial factors such as WSC and individual mental health. Sixth, we cannot reject the possibility of 'reverse causation' between WSC and psychological distress on the basis of our study design, since the changes in exposure and outcome were assessed simultaneously.

Our study has several strengths, including the large sample of Japanese employees, and the use of a new statistical method, a multilevel analysis using three levels (repeated measurements of psychological distress nested within individual employees, then work units). Based on these analyses, our study provides a new research insight into the contextual effect of WSC on employees' mental health.

\section{CONCLUSIONS}

This prospective study adds to previous research by showing that WSC is associated with improvement in mental health among employees. WSC appears to have a contextual effect on employees' mental health. We recommend that unit-level WSC is considered alongside other known contextual influences on the mental health of workers. To prevent mental health problems in subordinates, work unit managers might have a role in boosting WSC, such as organising athletic competitions within the company and social activities (eg, weekend corporate retreats and cherry blossom viewing picnic parties).

Acknowledgements The authors thank Melissa Leffler, MBA, from Edanz Group ( www.edanzediting.com/ac) for editing a draft of this manuscript.

Contributors HE performed the statistical analysis and drafted the manuscript. AT and Al conceived and conducted the study. IK and $\mathrm{HH}$ conceived the study and helped to draft the manuscript. All authors read and approved the final version of the manuscript and agreed to be accountable for all aspects of the work.

Funding This study was supported by a Grant-in-Aid for Scientific Research on Innovative Areas (Research in a Proposed Research Area) 2009-2013 (No. 4102 21119001) from the Japan Ministry of Education, Culture, Sports, Science and Technology, by JSPS KAKENHI Grant Number 26253042, and by the Work-related Diseases Clinical Research Grant 2018 (180701-01) from the Ministry of Health, Labour and Welfare, Japan.

Competing interests None declared.

Patient consent Obtained.

Ethics approval The study aims and protocol were reviewed by the Research Ethics Committee of the Graduate School of Medicine and Faculty of Medicine, The University of Tokyo (No. 2772), the Kitasato University Medical Ethics Organization (B12-103), and the Ethics Committee of the University of Occupational and Environmental Health, Japan (No. 10-004).

Provenance and peer review Not commissioned; externally peer reviewed.

Data sharing statement Because the data are still in process to transfer to a data archiving organisation, the ad hoc committee chaired by Prof Akizumi Tsutsumi is taking care of this role. Data are from the occupational cohort study on social class and health conducted in Japan (Japanese Study of Health, Occupation, and Psychosocial Factors Related Equity: J-HOPE) whose authors may be contacted at akizumi@kitasato-u.ac.jp.

Open access This is an open access article distributed in accordance with the Creative Commons Attribution Non Commercial (CC BY-NC 4.0) license, which permits others to distribute, remix, adapt, build upon this work non-commercially, and license their derivative works on different terms, provided the original work is properly cited, appropriate credit is given, any changes made indicated, and the use is non-commercial. See: http://creativecommons.org/licenses/by-nc/4.0/.

\section{REFERENCES}

1. Kawachi I, Berkman L, cohesion S. social capital, and health. In: Kawachi I, Berkman L, Glymour MM, eds. Social epidemiology second edition. New York: Oxford University Press, 2014:290-319.

2. Oksanen TSE, Takao S, Vahtera J, et al. Workplace social capital and health. In: Kawachi I, Takao S, Subramanian S, eds. Global perspectives on social capital and health. New York: Springer, 2013:23-63.

3. Wulsin L, Alterman T, Timothy Bushnell P, et al. Prevalence rates for depression by industry: a claims database analysis. Soc Psychiatry Psychiatr Epidemiol 2014;49:1805-21.

4. Török E, Clark AJ, Jensen JH, et al. Work-unit social capital and long-term sickness absence: a prospective cohort study of 32053 hospital employees. Occup Environ Med 2018;75:623-9.

5. Sapp AL, Kawachi I, Sorensen G, et al. Does workplace social capital buffer the effects of job stress? A cross-sectional, multilevel analysis of cigarette smoking among U.S. manufacturing workers. J Occup Environ Med 2010;52:740-50.

6. Oshio T, Inoue A, Tsutsumi A. The mediating and moderating effects of workplace social capital on the associations between adverse work characteristics and psychological distress among Japanese workers. Ind Health 2014;52:313-23.

7. Oksanen T, Kouvonen A, Vahtera J, et al. Prospective study of workplace social capital and depression: are vertical and horizontal components equally important? J Epidemiol Community Health 2010;64:684-9. 
8. Liukkonen V, Virtanen P, Kivimäki M, et al. Social capital in working life and the health of employees. Soc Sci Med 2004;59:2447-58.

9. Kouvonen A, Oksanen T, Vahtera J, et al. Low workplace social capital as a predictor of depression: the Finnish Public Sector Study. Am J Epidemiol 2008;167:1143-51.

10. Jung J, Ernstmann N, Nitzsche A, et al. Exploring the association between social capital and depressive symptoms: results of a survey in German information and communication technology companies. $J$ Occup Environ Med 2012:54:23-30.

11. Tsuboya T, Tsutsumi A, Kawachi I. Change in psychological distress following change in workplace social capital: results from the panel surveys of the J-HOPE study. Occup Environ Med 2015;72:188-94.

12. Sakuraya A, Imamura K, Inoue A, et al. Workplace social capital and the onset of major depressive episode among workers in Japan: a 3-year prospective cohort study. J Epidemiol Community Health 2017;71:606-12.

13. Inoue A, Kawakami N, Eguchi H, et al. Buffering effect of workplace social capital on the association of job insecurity with psychological distress in Japanese employees: a cross-sectional study. J Occup Health 2016;58:460-9.

14. Takahashi M, Tsutsumi A, Kurioka S, et al. Occupational and socioeconomic differences in actigraphically measured sleep. $J$ Sleep Res 2014;23:458-62.

15. Lindström M, The GGN. financial crisis: Changes in social capital and its association with psychological wellbeing in the United Kingdom-A panel study. Soc Sci Med 2008;2016:71-80.

16. Saurina $C$, Bragulat $B$, Saez M, et al. A conditional model for estimating the increase in suicides associated with the 2008-2010 economic recession in England. $J$ Epidemiol Community Health 2013;67:779-87.

17. Eguchi H, Shimazu A, Kawakami N, et al. Source-specific workplace social support and high-sensitivity C-reactive protein levels among Japanese workers: A 1-year prospective cohort study. Am J Ind Med 2016;59:676-84.

18. Kessler RC, Andrews G, Colpe LJ, et al. Short screening scales to monitor population prevalences and trends in non-specific psychological distress. Psychol Med 2002;32:959-76.

19. Furukawa TA, Kawakami N, Saitoh M, et al. The performance of the Japanese version of the K6 and K10 in the World Mental Health Survey Japan. Int J Methods Psychiatr Res 2008;17:152-8.

20. Eguchi $H$, Tsutsumi A, Inoue A, et al. Psychometric assessment of a scale to measure bonding workplace social capital. PLoS One 2017;12:e0179461.

21. Brännlund A, Hammarström A. Higher education and psychologica distress: a 27-year prospective cohort study in Sweden. Scand J Public Health 2014;42:155-62.

22. Atlantis E, Baker M. Obesity effects on depression: systematic review of epidemiological studies. Int J Obes 2008;32:881-91.

23. Stansfeld SA, Fuhrer R, Shipley MJ, et al. Work characteristics predict psychiatric disorder: prospective results from the Whitehall II Study. Occup Environ Med 1999;56:302-7.

24. Wada K, Kondo N, Gilmour S, et al. Trends in cause specific mortality across occupations in Japanese men of working age during period of economic stagnation, 1980-2005: retrospective cohort study. BMJ 2012:344

25. Kachi Y, Otsuka T, Kawada T. Precarious employment and the risk of serious psychological distress: a population-based cohort study in Japan. Scand J Work Environ Health 2014;40:465-72.

26. Watanabe K, Imamura K, Kawakami N. Working hours and the onset of depressive disorder: a systematic review and meta-analysis. Occup Environ Med 2016;73:877-884.

27. Garratt EA, Chandola T, Purdam K, et al. The interactive role of income (material position) and income rank (psychosocial position) in psychological distress: a 9-year longitudinal study of 30,000 UK parents. Soc Psychiatry Psychiatr Epidemiol 2016;51:1361-72.

28. Katon W, Ciechanowski P. Impact of major depression on chronic medical illness. J Psychosom Res 2002;53:859-63.

29. Carter KN, van der Deen FS, Wilson N, et al. Smoking uptake is associated with increased psychological distress: results of a national longitudinal study. Tob Control 2014;23:33-8.

30. Degenhardt L, Hall W, Lynskey M. Alcohol, cannabis and tobacco use among Australians: a comparison of their associations with other drug use and use disorders, affective and anxiety disorders, and psychosis. Addiction 2001;96:1603-14.

31. Danielsson L, Noras AM, Waern M, et al. Exercise in the treatment of major depression: a systematic review grading the quality of evidence. Physiother Theory Pract 2013;29:573-85.

32. Kawakami N, Kobayashi F, Araki S, et al. Assessment of job stress dimensions based on the job demands- control model of employees of telecommunication and electric power companies in Japan: reliability and validity of the Japanese version of the Job Content Questionnaire. Int J Behav Med 1995;2:358-75.

33. Landsbergis PA, Schnall PL, Warren K, et al. Association between ambulatory blood pressure and alternative formulations of job strain. Scand J Work Environ Health 1994;20:349-63.

34. International Labour Organization. International classification of occupations: ISCO-08. Geneva: International Labour Office, Geneva, 2012. (Accessed 20 Feb 2018).

35. Diez Roux AV. A glossary for multilevel analysis. J Epidemiol Community Health 2002;56:588-94.

36. McGraw KO, Wong SP. Forming inferences about some intraclass correlation coefficients. Psychol Methods 1996;1:30-46.

37. James LR, Demaree RG, Wolf G. Estimating within-group interrater reliability with and without response bias. J Appl Psychol 1984;69:85-98.

38. LeBreton JM, Senter JL. Answers to 20 questions about interrater reliability and interrater agreement. Organ Res Methods 2008;11:815-52.

39. Oksanen T, Kouvonen A, Kivimäki M, et al. Social capital at work as a predictor of employee health: multilevel evidence from work units in Finland. Soc Sci Med 2008;66:637-49.

40. Oyserman D, Coon HM, Kemmelmeier M. Rethinking individualism and collectivism: evaluation of theoretical assumptions and metaanalyses. Psychol Bull 2002;128:3-72.

41. Brislin RW, MacNab B, Worthley R, et al. Evolving perceptions of Japanese workplace motivation an employee-manager comparison. Int J Cross Cult Manag 2005;5:87-104.

42. Hansen AK, Madsen IEH, Thorsen SV, et al. Does workplace social capital protect against long-term sickness absence? Linking workplace aggregated social capital to sickness absence registry data. Scand J Public Health 2018;46:290-6.

43. Oksanen T, Kawachi I, Kouvonen A, et al. Workplace determinants of social capital: cross-sectional and longitudinal evidence from a Finnish cohort study. PLoS One 2013;8:e65846.

44. Murayama H, Fujiwara Y, Kawachi I. Social capital and health: a review of prospective multilevel studies. J Epidemiol 2012;22:179-87.

45. Gloede TD, Hammer A, Ommen O, et al. Is social capital as perceived by the medical director associated with coordination among hospital staff? A nationwide survey in German hospitals. $J$ Interprof Care 2013;27:171-6.

46. Kobayashi T, Suzuki E, Oksanen T, et al. The bright side and dark side of workplace social capital: opposing effects of gender on overweight among Japanese employees. PLoS One 2014;9:e88084.

47. Rosenquist JN, Fowler JH, Christakis NA. Social network determinants of depression. Mol Psychiatry 2011;16:273-81.

48. Pronyk PM, Harpham T, Busza J, et al. Can social capital be intentionally generated? a randomized trial from rural South Africa. Soc Sci Med 2008;67:1559-70.

49. Flores EC, Fuhr DC, Bayer AM, et al. Mental health impact of social capital interventions: a systematic review. Soc Psychiatry Psychiatr Epidemiol 2018;53:107-19.

50. Giorgi G, Perminienè M, Montani F, et al. Detrimental effects of workplace bullying: Impediment of self-management competence via psychological distress. Front Psychol 2016;7:60.

51. Shelley WW, Pickett JT, Mancini C, et al. Race, Bullying, and Public Perceptions of School and University Safety. J Interpers Violence 2017. 088626051773627.

52. Giorgi G, Arcangeli G, Mucci N, et al. Economic stress in the workplace: The impact of fear of the crisis on mental health. Work 2015;51:135-42.

53. Mucci N, Giorgi G, Roncaioli M, et al. The correlation between stress and economic crisis: a systematic review. Neuropsychiatr Dis Treat 2016;12:983-93

54. Wahlbeck K, McDaid D. Actions to alleviate the mental health impact of the economic crisis. World Psychiatry 2012;11:139-45. 